\title{
A Scenario Analysis of Solar Photovoltaic Grid Parity in the Maldives: The Case of Malahini Resort
}

\author{
Tae Yong Jung ${ }^{1}$, Donghun Kim ${ }^{1, *}$, Jongwoo Moon ${ }^{2} \mathbb{D}$ and SeoKyung Lim ${ }^{1}$ \\ 1 Graduate School of International Studies, Yonsei University, Seoul 03722, Korea; \\ tyjung00@yonsei.ac.kr (T.Y.J.); seokyung.lim@gmail.com (S.L.) \\ 2 Research Center for Global Sustainability, Institute for Global Engagement \& Empowerment, \\ Yonsei University, Seoul 03722, Korea; slide1234@yonsei.ac.kr \\ * Correspondence: dhkim2@yonsei.ac.kr; Tel.: +82-2-2123-6287
}

Received: 10 October 2018; Accepted: 2 November 2018; Published: 5 November 2018

check for updates

\begin{abstract}
The Maldives, one of the Small Island Developing States (SIDS) with great solar potential, is keen to promote renewable energy systems to reduce its heavy reliance on imported diesel for power generation. However, adopting renewable energy systems is still burdensome for the Maldives not only because of its high initial costs and insufficient financial resources but also because of a lack of understanding about whether the deployment of a renewable system is economically feasible. Therefore, the concept of grid parity is explored as an important concept in this paper to examine the possible timeframe for reaching it. A distinctive feature of the paper is that the paper used actual cost and technical information to analyze the levelized cost of energy (LCOEs) of the independent renewable system in a remote island and examined its timeframe for reaching the grid parity condition. Based on economic and technical information from a project for replacing existing diesel generator to photovoltaic (PV) with energy storage system (ESS) in Kuda Bandos Island in the Maldives, the paper considers three different system configurations and evaluates which configuration could result in the most optimal off-grid energy systems in this remote island. With sensitivity analysis on various uncertainties, the paper shows the range of the levelized costs of energy and the periods required for reaching grid parity for deploying solar photovoltaics and ESSs in Kuda Bandos Island, Maldives. The result indicates that the photovoltaic system is an economically feasible option for the resort, and that grid parity can be reached within the project lifetime. However, the result shows that the use of advanced ESSs is still an expensive option and would not be economically reasonable.
\end{abstract}

Keywords: levelized cost of energy; photovoltaic with energy storage system; HOMER simulation; LCOE comparison; sensitivity analysis

\section{Introduction}

In most remote islands, centralized generation of electricity is nearly impossible due to their unique conditions, and it makes diesel generation the primary source for power generation. High dependence on diesel price puts a huge economic and environmental burden on Small Island Developing States (SIDS). Reducing heavy reliance on imported diesel for power generation has been an important agenda for SIDS. This challenge has been encouraging SIDS to increase the deployment of renewable energy systems [1]. The recent technology development provides opportunities for the Maldives to deploy more renewable energy systems by reducing the costs of solar photovoltaics (PV) with or without energy storage systems (ESS) as well as increasing their efficiencies [2]. However, adopting renewable energy systems is still burdensome for the Maldives because of its initial costs and insufficient financial resources. Also, the countries lack understanding about whether a renewable system is an economically feasible option compared to conventional energy systems. Since the countries 
have limited financial resources and capacity, the economic feasibility is inevitably an important factor for the selection of energy systems. Therefore, achieving grid parity where the cost of renewables becomes the same or less than that of conventional sources is an important milestone for the successful diffusion of renewables in SIDS.

Reducing high diesel dependence and adopting renewable systems are also an important national agenda for the Maldives, one of the SIDS. The Maldives is in the Indian Ocean and is composed of more than 1000 islands. Due to its location in tropical zones, the Maldives has a high potential for solar systems. The country reached $100 \%$ electrification rate, but the dominant system is still off-grid diesel generation. The Maldives has established an ambitious target of achieving $100 \%$ renewable energy by 2020 in 2009 and encouraged the deployment of renewable systems [3]. However, the pace of the deployment of renewable systems has been slow, and only $1.28 \%$ of electricity generated is provided by renewables [4].

The paper examines the possible timeframe for reaching grid parity in a SIDS country from the case project of replacing an existing diesel generator to photovoltaic power generation with ESS in a resort on Kuda Bandos Island, Maldives. Kuda Bandos Island is located near Male, the capital of the Maldives. The main economic activity of the island is tourism, so the resort on the island has demands for establishing a sustainable energy system. Also, this small island is remote from other islands, and the resort is the only demand source for energy. Thus, both the reliability and economic feasibility of the energy system are important. The project is funded by the Korea Institute of Energy Technology Evaluation and Planning and the Ministry of Trade, Industry, and Energy of the Republic of Korea. The purpose of the project is to replace the existing diesel generator to PV with ESS and diesel generator. The project implements the installation of PV $290 \mathrm{~kW}$ with Power Conversion System (PCS) $295 \mathrm{~kW}$, $728 \mathrm{kWh}$ Lithium battery and $250 \mathrm{kWh}$ Vanadium Redox Flow Battery (VRFB). The objective of the project is to develop advanced VRFB and implement the independent renewable system on the island. Thus, the paper tests the system's technical feasibility and compares levelized cost of energy (LCOEs) of three different systems, which are existing diesel generation, solar photovoltaic systems with diesel generators, and solar photovoltaic systems with ESSs based on the information given from the resort and the companies providing system components. The study uses costs, such as logistics, technology, construction, and operations costs, and system specifications from the case project. Since the project site is a remote island and requires a self-sufficient energy system, the project contains additional issues, such as including logistics costs and operations and maintenance issues. Thus, the concept of grid parity would be applied to the comparison among LCOEs of feasible options. The study examines the timeframe for reaching grid parity for those renewable systems compared to the existing diesel generation. Examining LCOEs of different system settings, including ESS, and their timeframe for reaching grid parity, can contribute to accelerating deployment of renewable systems in the Maldives as well as other SIDS countries. Furthermore, the results can provide further implications to other islands in the Maldives, those have similar characteristics, such as remote island and a self-sufficient diesel generation, to the case projects.

\section{Literature Review}

In the literature, various papers studied the economic and technical feasibility of sustainable energy systems in developing countries and SIDS. The objectives of the studies were to find the optimal independent renewable system and demonstrate the economic and financial feasibility of the selected system. (Jung et al. (2017) [5]; Ali et al. (2018) [6]; and Kaldellis et al. (2009) [7]) Jung et al. (2017) and Ali et al. (2018) both examined technical and economic feasibilities of independent PV systems on the islands of the Maldives by Hybrid Optimization of Multiple Electric Renewables (HOMER) simulations and demonstrated that the PV system is a feasible option to replace the diesel generation of the small islands in the Maldives. In addition, Kalidellis et al. (2009) found the optimal PV-ESS system configuration, as Jung et al. (2017) did, for small remote islands and conducted a cost-benefit analysis. The study also confirmed that the optimal renewable system with ESS can be considered 
as an effective option for solving electrification issues on remote islands, especially located in high and medium-high solar potential regions [7]. Though those studies demonstrated the technical and economic feasibility of the independent renewable systems, those analyses limitedly consider the timeframe for reaching grid parity condition of renewable systems. Therefore, the analysis of the paper can contribute to providing additional information when the grid parity condition of independent renewable systems can be reached in remote islands.

Moreover, the optimal selection and the management of renewable systems are essential parts for understanding economic feasibility of the renewable systems. In particular, the recent progress in computational simulation capacity allowed the introduction of the advanced methodologies in achieving optimal management of renewable systems with ESSs. Though this paper analyzes based on a project with a pre-determined renewable system configuration, Rangel et al. (2018) presented a methodology for choosing an optimal size, type, and site of ESS. The purpose of the study was to obtain the optimal charge and discharge strategy and find the best cost option [8]. Ghanaatian and Lotfifard (2018) proposed a method for the optimal control of the flywheel ESS by using a tube-based Model Predictive Control (MPC) model. The study included uncertainties and external disturbances in the model and conducted simulations to show the effectiveness of the model [9]. Li and Hennessy (2013) conducted a study to reduce grid dependence of midsize European town by adopting a large-scale PV, Wind, and VRFB. The study targeted to reduce grid dependence, grid purchase, and spilled wind lost and achieve shorter payback periods for the ESS. By considering different size of VRB-ESS, the study found the optimal size and technical specification of ESS that satisfies the objectives [10]. These studies were to find the optimal selection and management of the battery system that satisfy the optimal operation and the reliability of the renewable system. In addition, the advanced methodologies are presented for the management of multiple micro grid systems. Tavakoli et al. (2018) proposed a way to find an optimal management system of battery energy for the commercial building microgrid using a linear optimization programming with the Conditional Value at Risk (CVaR). This approach considers maximizing the management of microgrid photovoltaic system and battery energy while reducing key uncertainties, such as electricity price and power generation, in operating photovoltaic energy system with battery. It not only improves the efficient use of renewable energy system but also enhances the resilience of the commercial microgrid [11]. Marzband et al. (2018a) and Marzband et al. (2018b) demonstrated a smart Transactive Energy (TE) framework that established a coalition of multiple home microgrids and found an optimal resource management and profit sharing among the participants [12,13]. Marzband et al. (2018a) showed a smart TE framework that builds a coalition of multiple home microgrids and found an optimal way to achieve fair allocation of coalition profit. The study used a multi-stage stochastic programming based on artificial bee colony (MSSP-ABC) algorithm to simulate the formation of possible coalitions and find a "fair" distribution of profits. The simulation result demonstrated that the coalition encourages the participation of home microgrid owners and consumers in the deregulated market and contributes to mitigating electric load fluctuations [12]. Marzband et al. (2018b) used improved optimization techniques to solve the non-linear and non-convex Market Operator Transactive Energy (MO-TE) structure issue. The method proposed by the study was used to find the home microgrids' optimal electricity and thermal resources and maximize home microgrids owners' profits. This approach enables to find the optimal timing for home microgrids owners to exchange electricity and provides a chance to reduce the exploitation cost of home microgrids owners [13]. However, the case project used in this paper is a resort in a remote island with no grid connections to other islands, and the resort operates its self-sufficient energy system. Also, the pre-determined renewable system design was implemented in the resort. Thus, these advanced methodologies for optimal management of multiple home-grid systems as well as the selection of ESS are hard to be implemented in this case.

Along with feasibility studies of on-grid and off-grid renewable energy systems, various research has been undertaken on grid parity analysis. To compare the different types of energy technologies, LCOE calculation method is widely used in the grid party analysis. In the early 2010s, the studies 
showed that a solar PV system showed a great potential to be a feasible option in the future but reaching grid parity condition needed much more time. (Branker et al. (2011) [14]; Yang (2010) [15]; Lund (2011) [16]) However, the continued technological development made the on-grid and off-grid solar PV systems more attractive options, and the recent studies expected shorter timeframes for reaching grid parity of PV systems. Though the recent studies found that both off-grid and on-grid solar systems are still expensive options for developing countries (Baurzhan and Jenkins (2016) [17]; Zou et al. (2017) [18]), many studies found the grid parity of solar PV systems can be reached in countries within the next few decades. For instance, Zou et al. (2017) and Mundada et al. (2016) studied whether the off-grid PV systems can reach the grid parity condition in China and the US Zou et al. (2017) found optimal solar PV systems in five different Chinese cities and applied learning curves for calculating LCOEs. It found that the grid parity condition of off-grid PV systems in those Chinese cities can be reached in between about 2026 and 2050 [18]. Mundada et al. (2016) chose a residential sector in Houston, MI with an unfavorable environment for solar systems as a case study and calculated LCOE of off-grid PV with ESSs and combined heat and power (CHP) systems. The study showed that LCOEs of the hybrid system are lower than grid costs in many cases and argued that the hybrid system can be developed further in the US in the near future [19]. Moreover, there has been in-depth studies which included uncertainties in calculating LCOEs of PV systems. (Biondi and Moretto (2015) [20]; and Said et al. (2015) [21]) Biondi and Moretto (2015) examined solar grid parity in Italy by using a real option approach. The study evaluated uncertainties, such as energy prices and PV module costs, and demonstrated how those uncertainties affect the PV market in Italy. It showed that PV systems seem to achieve grid parity soon thanks to relatively high electricity tariffs and good solar radiation, but the uncertainties may delay grid parity condition in Italy for several years [20]. Said et al. (2015) presented an improved modeling of LCOE that used the effective lifetime of different types of PV technologies and different environmental or technical conditions. The study included the input data's uncertainties in the analysis and examined whether PV technologies reached grid parity in Egypt. It found the use of the effective lifetime affects LCOE and the total electricity generation during the lifetime [21].

Various studies on the levelized cost of energy are conducted on comparing LCOEs of different technologies in national level and on comparing LCOEs of grid-connected renewable systems to other conventional energy systems. However, in the countries composed of many islands, such as the Maldives, the grid connection among systems is nearly impossible, and the deployment of independent renewable systems have additional risk factors. This paper uses actual technology, logistics, construction, and operations costs from the project. Also, the paper applies the concept of the grid parity to the project in a remote island in the Maldives where the central grid system cannot be established. The findings from the paper can be further applied to other remote islands. Moreover, the paper conducts sensitivity analysis on key risk factors, such as changes in discount rate and diesel price, to examine how the external risk factors can affect the economic feasibilities and the grid parity conditions of renewable energy systems in the Maldives.

\section{Materials and Methods}

\subsection{System Design and Optimization}

Prior to examining the LCOEs of energy systems and the grid parity timeframe, HOMER software version 3.12 (HOMER Energy, Boulder, CO, USA) is used to find the optimal system configurations. HOMER software is a powerful tool developed by US National Renewable Energy Laboratory that simulates a viable system for all possible combinations of different energy systems based on their technical and economic merit [22]. HOMER can model grid-connected as well as off-grid power systems comprising any combination of wind turbines, PV arrays, fuel cells, small hydropower, biomass, converter, batteries, and conventional generators [23]. The simulated systems are sorted and filtered based on the criteria the user determines. Next, HOMER allows analysts to conduct sensitivity 
analyses and to examine the impacts of uncertainty and changes in input variables. This energy modeling software simulates multiple system combinations based on input variables such as monthly load, discount rate, and system costs and finds the optimal system designs, satisfying the technical constraints at the lowest net present cost [24]. The main objective of the HOMER simulation is to evaluate the economic and technical feasibility of renewable energy systems to be installed in a specific location based on given information of equipment and energy resource availability.

The simulation results show that three system configurations were found to be viable designs based on the input variables we entered, as shown in Figure 1. The system I represents a system design that uses only the existing diesel generator. System II represents a system configuration in which PV and diesel generators are used simultaneously, and System III is composed of PV, ESS and diesel generators.
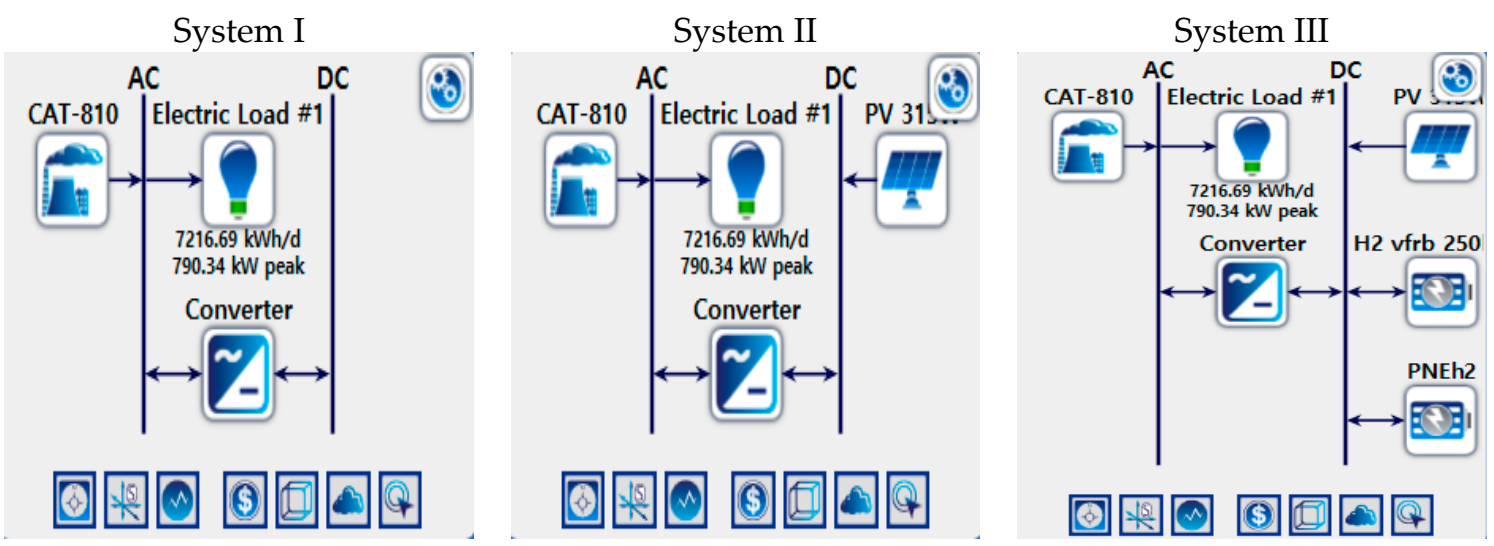

Source: HOMER Software

Figure 1. System Configuration.

\subsection{Site Specification and Load Patterns}

This study is conducted to replace existing diesel generators with either PV-only or PV with ESS in the Malahini Kuda Bandos resort located on Kuda Bandos Island, Maldives. The Malahini Kuda Bandos resort is the only resort in this small island, and the resort is self-satisfying its electric loads from a diesel generator. The resort has three diesel generators. However, operating one diesel generator at a time meets the electric loads of the resort. One of the two other diesel generators has to be operated manually if the electric load exceeds $500 \mathrm{~kW}$. This PV-ESS project was implemented to eliminate the inconvenience of turning on diesel generators manually.

The Maldives is hot and sunny all throughout the year, with average temperatures of 23 to 31 degrees Celsius. The high season falls between December and March, and the monsoon runs from May to October [25]. Despite fluctuations in weather condition, the Malahini Kuda Bandos resort has a constant and stable electric load throughout the year. Its monthly average of electric loads falls between $303.76 \mathrm{~kW}$ and $338.57 \mathrm{~kW}$.

\subsection{Assumptions and System Components}

This paper assesses the feasibility of two new technical options for replacing diesel generators operating at Kuda Bandos Island with either PV-only or PV-ESS. The capacity of PV is $290 \mathrm{~kW}$. The PCS that stores the power produced by Solar PV in the ESS system is $295 \mathrm{~kW}$. There are also two types of ESSs included in this project: a $728 \mathrm{~kW}$ Lithium-Ion Battery (LIB) type and a $250 \mathrm{~kW}$ VRFB type.

In addition to the assumptions of system components, various financial assumptions are considered. The debt-to-equity ratio is assumed to be 70:30 [26]. The rate of return for equity is assumed to be nominal at $13.5 \%$, and the debt rate is assumed to be $8.5 \%$. The inflation rate is set as $2.2 \%$, which is an average rate of the Maldives between 2013 and 2017 [27]. Based on these assumptions, the real discount rate is set as $7.8 \%$. The debt repayment period is set at 7 years, and the grace period is 
given as 1 year during the construction period. Operation and Maintenance $(\mathrm{O} \& \mathrm{M})$ costs are assumed to be $2 \%$ of the total system cost, and the O\&M costs are expected to rise at the same rate as the annual inflation rate. In terms of electricity generation, electricity generation from solar is assumed to decrease by $0.5 \%$ per year as solar panel performance declines, and diesel consumption per liter is calculated as electricity generated by diesel $(\mathrm{kWh})$ times $\mathrm{L} / \mathrm{kWh}$. We also assume that diesel prices are set at $\$ 1.06 / \mathrm{L}[28]$, which is equal to the world average, and we assume that annual diesel price rises every year at $2.2 \%$, which is equivalent to the inflation rate of the Maldives.

Based on this input data, the technical simulation shows the three possible system configurations at the Kuda Bandos Island. The possible system configurations are shown in Table 1. The base system configuration is a diesel-only system that uses the existing diesel generator already in operation at the resort (System I). Another possibility is to use the existing diesel generator and $290 \mathrm{~kW}$ PV together (System II), and the other option is to supply electricity to the resort using the existing diesel generator, $290 \mathrm{~kW}$ PV, and two types -LIB and VRFB of ESS (System III).

Table 1. System Configuration.

\begin{tabular}{ccccc}
\hline System & PV & PCS & ESS & Diesel \\
\hline System I & - & - & - & $648 \mathrm{~kW}$ \\
System II & $290 \mathrm{~kW}$ & $295 \mathrm{~kW}$ & - & $648 \mathrm{~kW}$ \\
System III & $290 \mathrm{~kW}$ & $295 \mathrm{~kW}$ & $978 \mathrm{kWh}$ & $648 \mathrm{~kW}$ \\
\hline
\end{tabular}

According to optimizations and simulations, in both System II and System III, PV provides approximately $472,428 \mathrm{kWh}$ for the first year and accounts for $17.1 \%$ of electricity generated from the entire system. As solar performance degrades $0.5 \%$ annually, the remaining amount of electricity required will be covered by additionally using diesel generator. The technical information indicates that the ESS is used to avoid the occurrence of capacity shortage and unmet electric load and reduce excess electricity. Without an ESS, $80,525 \mathrm{kWh}$ (2.92\% of total electricity generation) of electricity is considered to be excess electricity every year.

\section{Results}

\subsection{LCOE and Grid Parity}

To find the grid parity, this study calculated yearly LCOEs based on the technical information as well as financial assumptions. The LCOE methodology, which is the unit cost of the energy generated by a system over its lifetime is abstracted from reality and is used as a benchmarking or ranking tool to evaluate the cost-effectiveness of other energy generation technologies [29]. The LCOE method is useful in that it allows fair and direct comparison of different electricity generation technologies [30]. Because photovoltaic and ESSs require huge initial capital investments, both System II and System III start with very high LCOEs of 1.08 and 0.49 , respectively, as shown in Figure 2. Also, the debt interests and repayments occurred in the first 7 years make their LCOEs higher. As the system continues to generate more electricity, LCOEs continues to decrease. The study assumed the real diesel price to be fixed, LCOE of System I stays at $\$ 0.3208$ per $\mathrm{kWh}$. According to the study, LCOE of System II (PV + Diesel) reaches grid parity in 5.77 years (between 2022 and 2023). Afterward, it continues to decrease and has LCOE of $\$ 0.3056 / \mathrm{kWh}$ at the end of the project period.

However, this study finds that System III fails to reach grid parity. Adding ESS requires high system costs and financing costs, and it makes LCOE of the system very high. Though its LCOE decreases rapidly at the early stage, the difference between System III and System I is about $\$ 0.11 / \mathrm{kWh}$ in 2023 when System I reaches the grid parity condition. At the end of the project period, LCOE of System III reaches $\$ 0.3614 / \mathrm{kWh}$, and it is still $\$ 0.04 / \mathrm{kWh}$ higher than that of System III. This result is consistent with Yang (2010)'s conclusion that solar PV is much less cost effective in a distributed system. Yang attributed the result in the fact that many analysts did not amortized all the end-user 
costs and incorrectly considered the cost of $\$ 1 / \mathrm{W}$ as manufacturing costs instead of retail installation costs when calculating grid parity [15].

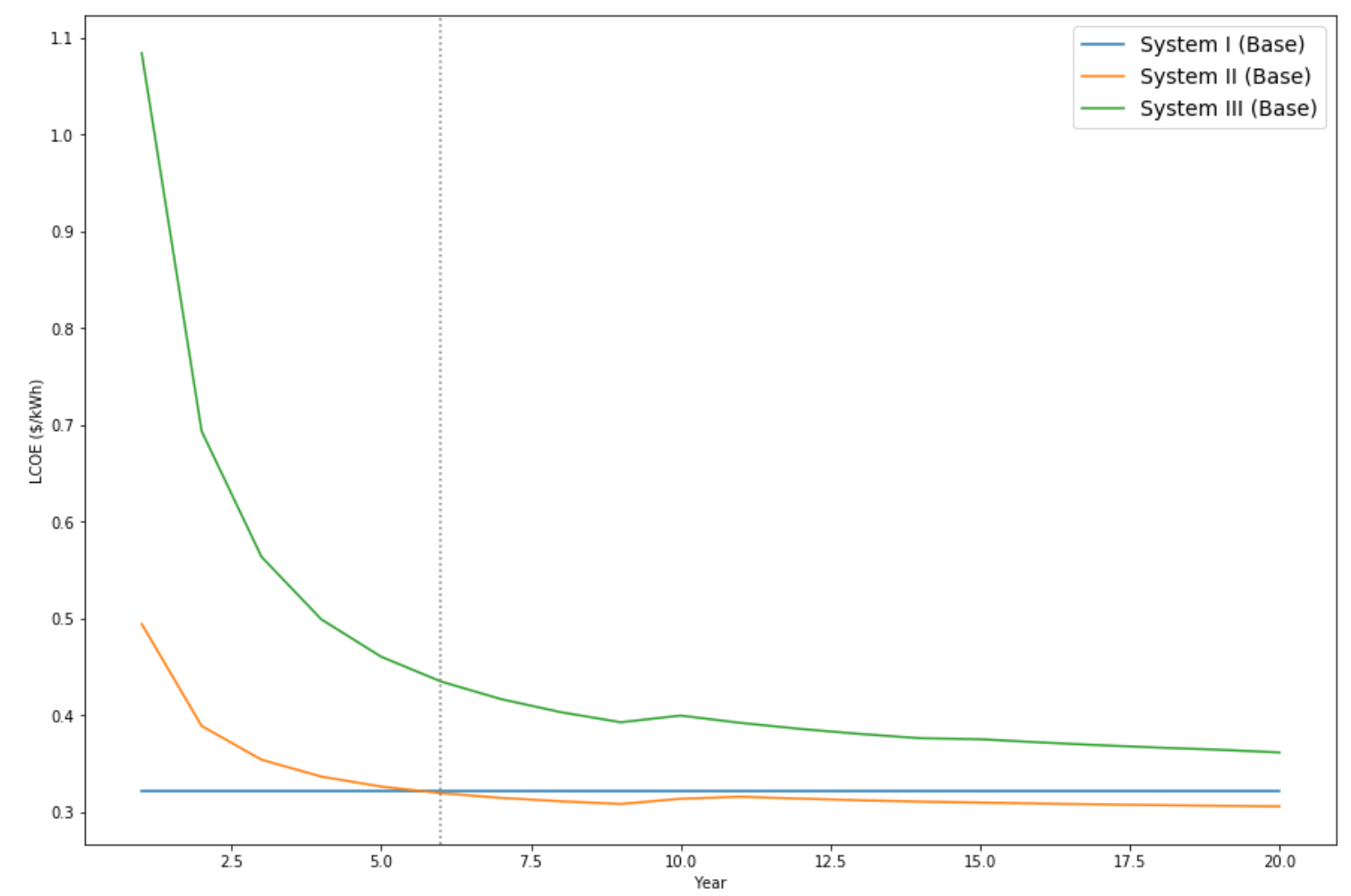

Figure 2. Yearly LCOEs of the Systems (Unit: $\$ / \mathrm{kWh}$ ).

\subsection{Sensitivity Analysis}

Installing off-grid renewable systems in SIDS can face various unexpected circumstances and these issues can increase project costs and threaten project operations. Thus, the study conducts a sensitivity analysis to examine how the changes in diesel prices and discount rates affect the systems' LCOEs. Table 2 shows the sensitivity analysis conditions considered in this study.

Table 2. Sensitivity Analysis Conditions.

\begin{tabular}{cccc}
\hline Sensitivity Analysis & & \\
\hline Discount Rate & $10 \%$ & & $12 \%$ \\
Diesel Price (Real) & $\$ 0.954(-10 \%)$ & $\$ 1.166(+10 \%)$ & $\$ 1.272(+20 \%)$ \\
\hline
\end{tabular}

\subsubsection{Discount Rate}

The project investors require the rate of return on their investments based on their perception of the project risk level. Local conditions and risk factors of installing and operating renewable systems in SIDS can make project investors to require a higher rate of return. To reflect it, the study conducts a sensitivity analysis on discount rate by altering the discount rate to $10 \%$ and $12 \%$. The value of the discount rate must be carefully assessed because it can influence the invertor decision towards one option or another. The value chosen for the discount rate can be influenced by the investor's choice and should be carefully assessed. Thus, we conduct a sensitivity analysis of discount rates based on the conservative discount rates assumed by the International Energy Agency, which are between 10\% and $12 \%$ for PV systems [31].

Table 3 and Figure 3 show the LCOEs of the three systems when the discount rate changes, and Figure 4 shows when the grid parity condition can be achieved at the different discount rates. 
If the discount rate increases to $10 \%$ from $7.8 \%$, LCOEs of the renewable systems increase slightly while LCOE of System I decreases to $\$ 0.3206 / \mathrm{kWh}$. Still, System II reaches grid parity, but it is delayed and occurs in 6.33 years (between 2023 and 2024). System III becomes more expensive and the LCOE gap between System III and System I becomes $\$ 0.05 / \mathrm{kWh}$ at the end of the project periods. If the discount rate increases up to 12\%, System II reaches grid parity in 6.95 years (between 2023 and 2024). This result is supported by the research of Simsek et al. (2018) demonstrating that debt fraction and discount rate illustrated significant sensitivities on both LCOE and government cost. By increasing discount rate from $6 \%$ to $12 \%$, the research of Simsek et al. (2018) also proves that both LCOE and government cost showed an increasing trend [32]. As the economic feasibility of the project depends highly on feed-in tariffs concessions, the Maldives' unstable political and legislative situations could negatively affect the discount rates of PV and ESS technologies. However, as the technology matures, and the solar PV markets evolve, the significance of discount rates will decline over time.

Table 3. LCOEs of the systems when the discount rate changes (Unit: $\$ / \mathrm{kWh}$ ).

\begin{tabular}{cccc}
\hline Sensitivity Analysis (Discount Rate) & $\mathbf{7 . 8} \%$ & $\mathbf{1 0} \%$ & $\mathbf{1 2} \%$ \\
\hline LCOEs (System I) & 0.3208 & 0.3206 & 0.3204 \\
LCOEs (System II) & 0.3056 & 0.3085 & 0.3113 \\
LCOEs (System III) & 0.3614 & 0.3735 & 0.3851 \\
\hline
\end{tabular}

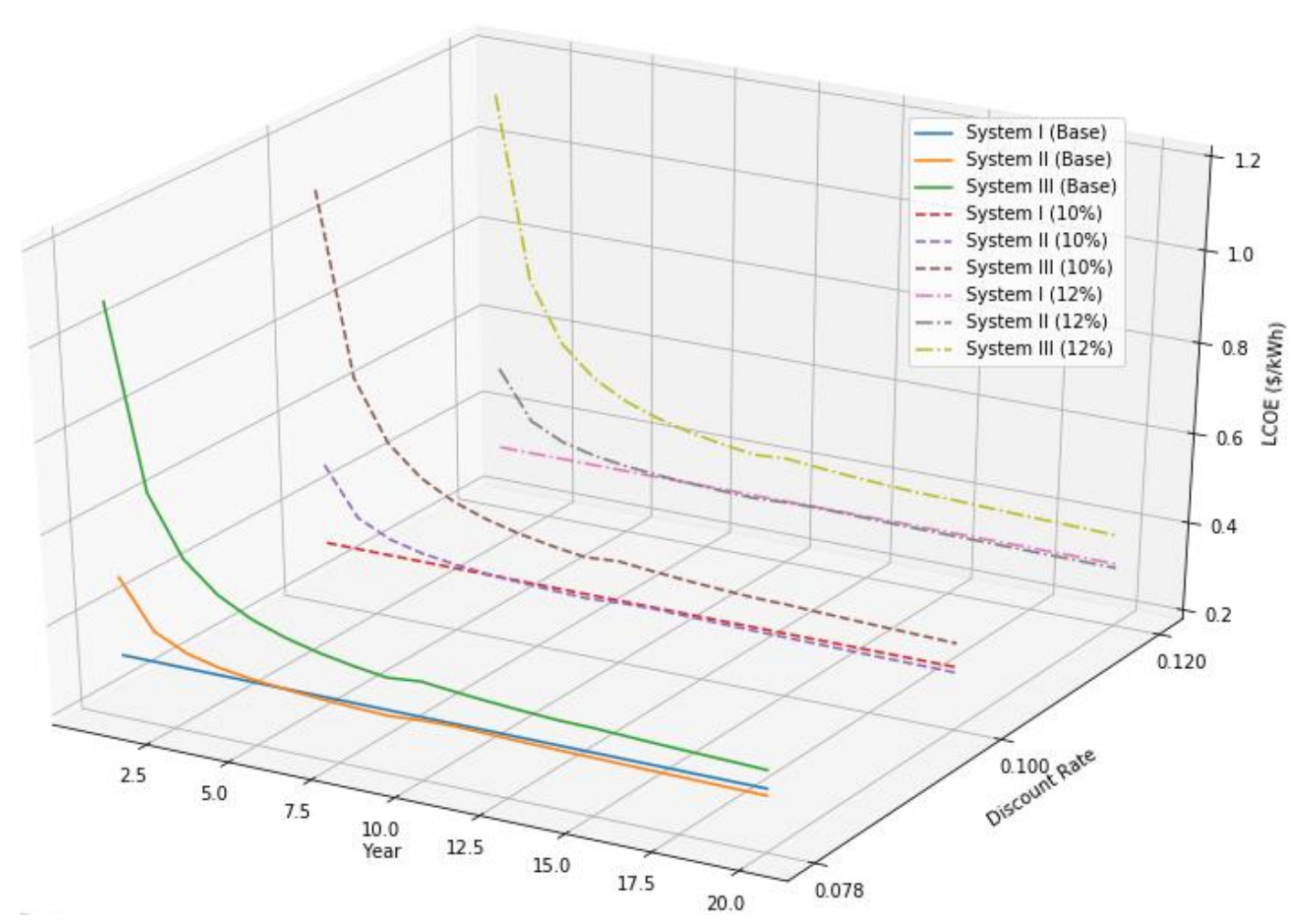

Figure 3. Yearly LCOEs if Discount Rate changes. 


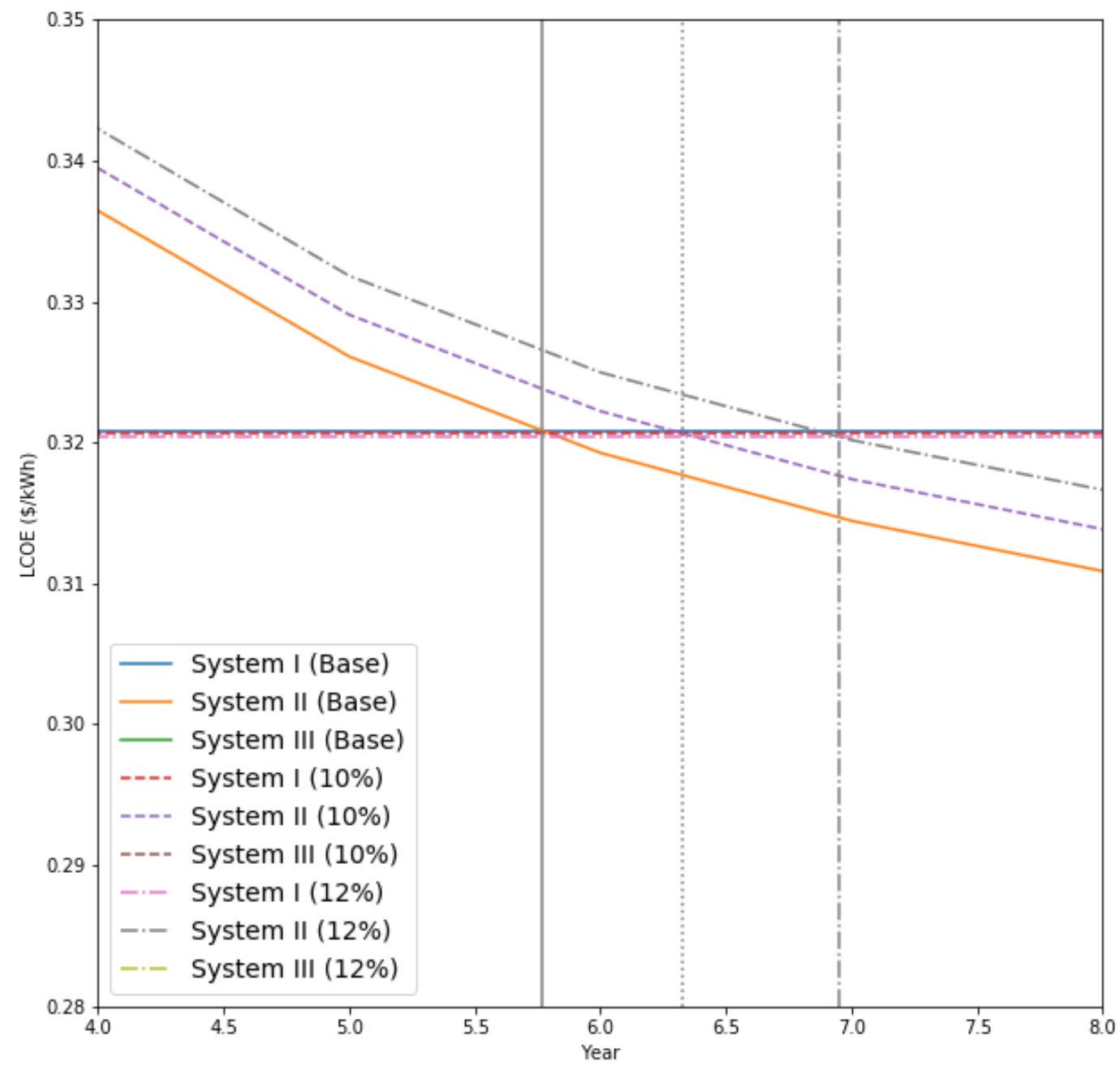

Figure 4. Grid Parity (Sensitivity Analysis on Discount Rate).

\subsubsection{Diesel Prices}

Due to all systems using a large portion of diesel generation, the changes in diesel prices can affect LCOEs of the systems significantly. In particular, under the circumstances of increasing global diesel prices in recent years, the increase in diesel price can increase LCOEs of the project.

Table 4 and Figure 5 show the LCOEs of the systems when the diesel price changes, and Figure 6 shows when the grid parity condition can be achieved at the different diesel prices. If the diesel price decreases to $\$ 0.954 / \mathrm{L}$, LCOEs of the systems also decrease. Grid parity of System II can be reached in 6.6 years (between 2023 and 2024). However, System III cannot reach grid parity. On the other hand, if the diesel price increases by $10 \%$ and becomes $\$ 1.166 / \mathrm{L}$, grid parity of System II is reached in 5.11 years (between 2022 and 2023). Also, the LCOE difference between System III and System I reduces to $\$ 0.035 / \mathrm{kWh}$. If the diesel price further increases to $\$ 1.272 / \mathrm{L}$, the grid parity condition of System II can be achieved earlier. Grid parity is achieved in 4.64 years (between 2021 and 2022). This indicates that the project is likely to benefit if the recent trends of increasing global oil price continue and the diesel price of the Maldives increases. This result is supported by research done by Peerapong and Limmeechokchai who conducted a sensitivity analysis using variations such as solar radiations, cost of diesel prices, real interest rates and load consumptions. The variations of diesel prices set from $\$ 0.9 / \mathrm{L}$ to $\$ 1.2 / \mathrm{L}$ affect NPC, COE, and renewable shares in the system. The study finally concludes that minimum diesel price should be at least $\$ 0.561 / \mathrm{L}$ for the hybrid diesel/PV system with ESS to compete with the diesel-only existing system [33]. 
Table 4. LCOEs of the systems when the diesel price changes (Unit: (Diesel) \$/L; (LCOE) \$/kWh).

\begin{tabular}{cccc}
\hline Sensitivity Analysis (Diesel Price) & $\mathbf{\$ 0 . 9 5 4}$ & $\mathbf{\$ 1 . 1 6 6}$ & $\mathbf{\$ 1 . 2 7 2}$ \\
\hline LCOEs (System I) & 0.2907 & 0.3509 & 0.3810 \\
LCOEs (System II) & 0.2799 & 0.3314 & 0.3571 \\
LCOEs (System III) & 0.3365 & 0.3862 & 0.4111 \\
\hline
\end{tabular}

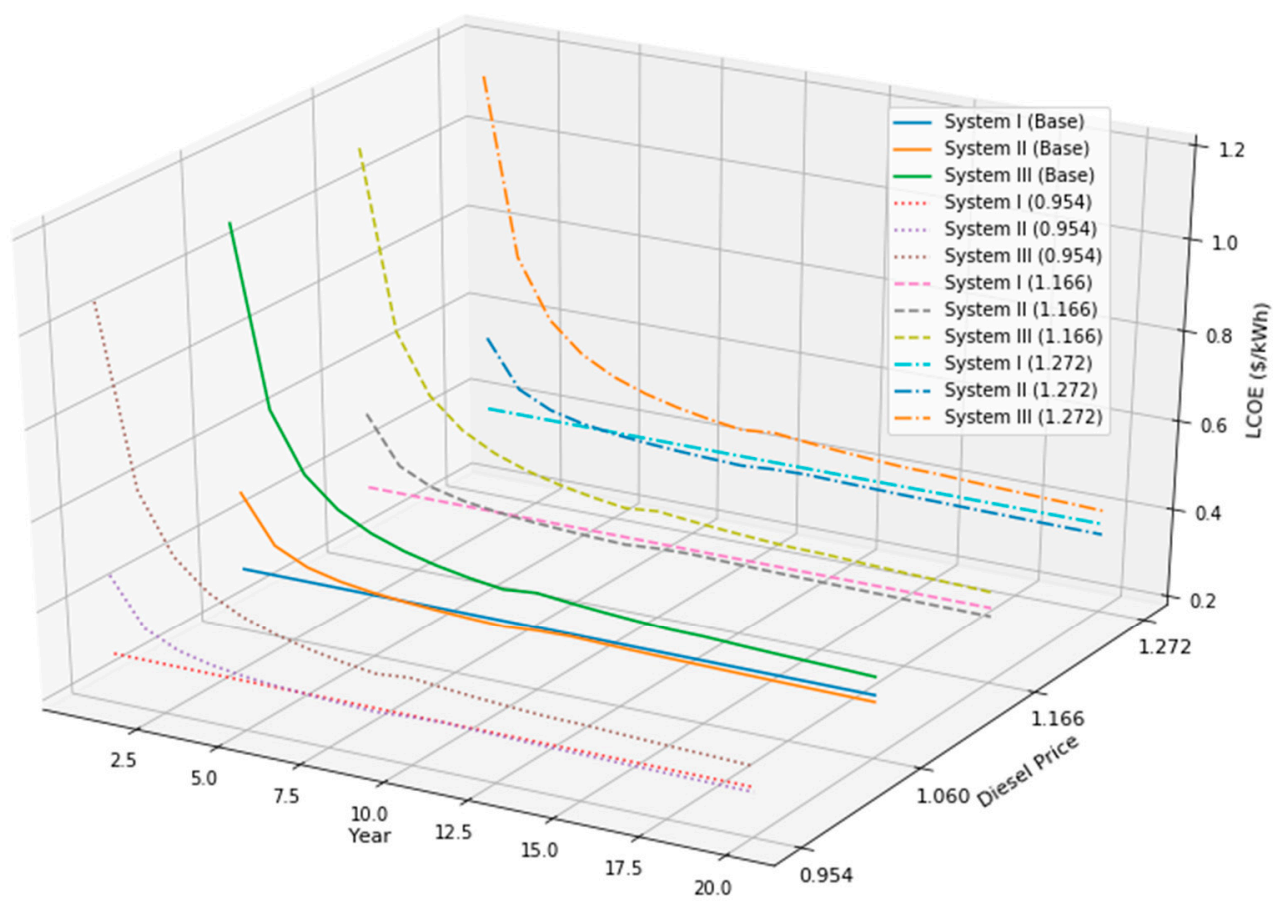

Figure 5. Yearly LCOEs when Diesel Price changes.

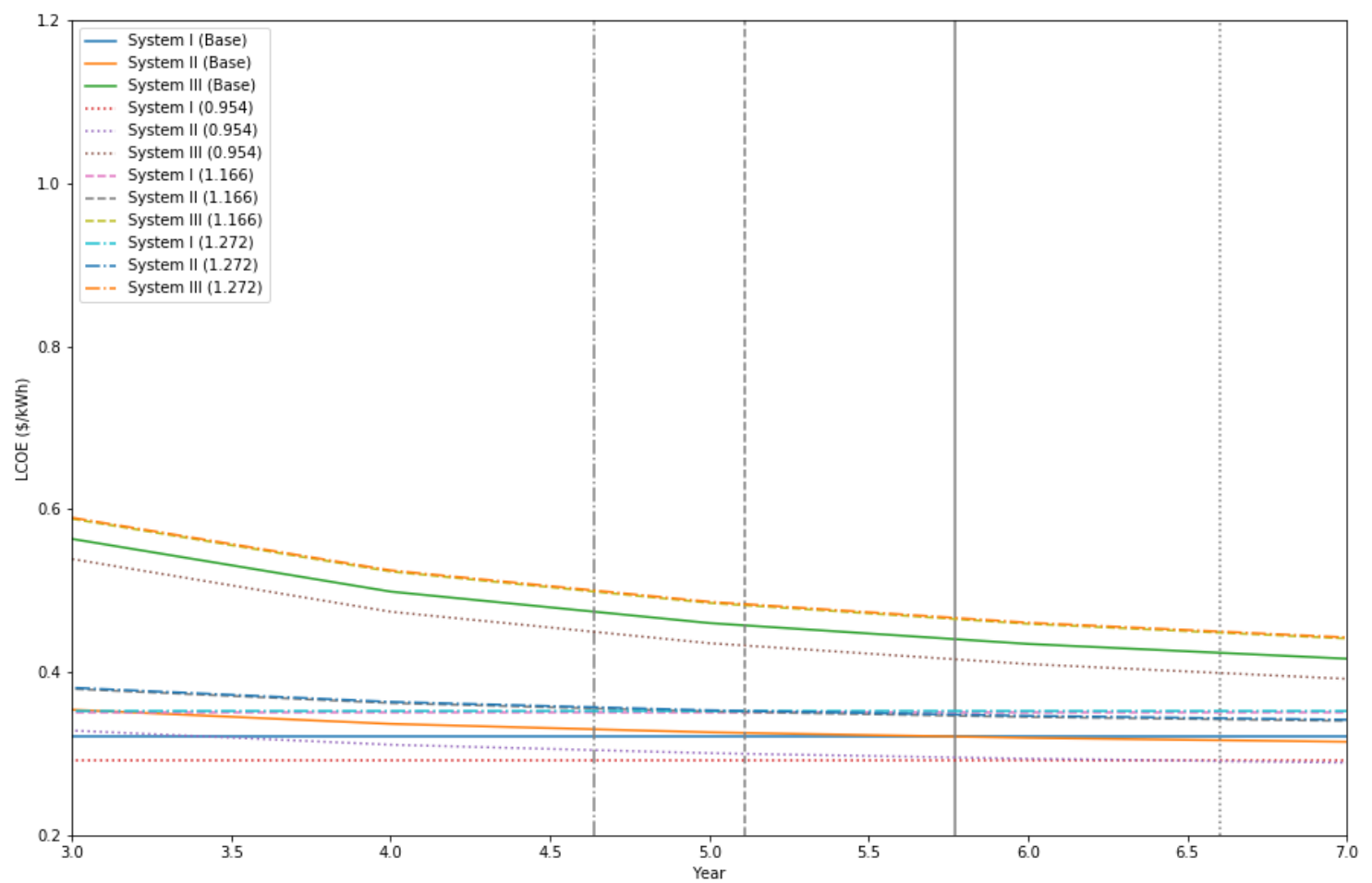

Figure 6. Grid Parity (Sensitivity Analysis on Diesel Price). 


\subsubsection{Summary of Sensitivity Analysis}

The sensitivity analysis shows the time required to reach grid parity if the diesel price and discount rate change, and the detailed results of the sensitivity analysis are shown in Table 5 . Though the analysis indicates that the system design with an ESS cannot reach grid parity, System II reaches grid parity mostly within 7 years. If the diesel price goes down and the discount rate increases, System II requires more time to reach the grid parity as shown in Table 6. An increase in diesel price benefits the renewable systems consuming less diesel, and an increase of discount rate, which means the project is perceived as a riskier one, can make the renewable systems less attractive.

Table 5. Summary of Results.

\begin{tabular}{ccccc}
\hline \multicolumn{2}{c}{ LCOEs } & System I & System II & System III \\
\hline$@ 7.8 \%$ & $\$ 1.06$ & 0.3208 & 0.3056 & 0.3614 \\
$@ 7.8 \%$ & $\$ 0.954$ & 0.2907 & 0.2799 & 0.3365 \\
$@ 7.8 \%$ & $\$ 1.166$ & 0.3509 & 0.3314 & 0.3862 \\
$@ 7.8 \%$ & $\$ 1.272$ & 0.3810 & 0.3571 & 0.4111 \\
$@ 10 \%$ & $\$ 1.06$ & 0.3206 & 0.3085 & 0.3735 \\
$@ 12 \%$ & $\$ 1.06$ & 0.3204 & 0.3113 & 0.3851 \\
\hline
\end{tabular}

Table 6. When the Grid Party can be reached (System II).

\begin{tabular}{ccccc}
\hline Sensitivity Analysis & $\mathbf{\$ 0 . 9 5 4}$ & $\mathbf{\$ 1 . 0 6}$ & $\mathbf{\$ 1 . 1 6 6}$ & $\mathbf{\$ 1 . 2 7 2}$ \\
\hline $7.8 \%$ & 6.6 years & 5.77 years & 5.11 years & 4.64 years \\
$10 \%$ & 7.35 years & 6.33 years & 5.58 years & 4.95 years \\
$12 \%$ & 8.25 years & 6.95 years & 6.01 years & 5.35 years \\
\hline
\end{tabular}

\section{Discussion}

The study examined whether renewable systems are feasible options in SIDS based on the case of the Kuda Bandos Island, Maldives. Also, the study used the LCOE method to find when the grid parity condition can be met. The case project is to replace the existing diesel generator to a solar photovoltaic system with ESS and diesel generator.

Though the project included two types of energy storage systems, the sensitivity analysis showed that the grid parity of PV with ESS is hard to be reached within the project lifetime. However, if the project only uses solar PV and diesel generator, the grid parity can be reached in 5.77 years, and the renewable system is an effective solution for replacing the existing diesel generator and reducing diesel consumption. Moreover, in all cases, the sensitivity analysis showed that solar PV and diesel generator (System II) reaches the grid parity condition. Thus, the paper demonstrates that solar PV already reached the grid parity condition and became an effective solution for achieving the renewable target of the Maldives and reducing the heavy dependence on imported fossil fuel.

The results of the sensitivity analysis indicate that the discount rate and diesel price are major factors affecting the economic feasibilities of renewable systems and the grid parity conditions. The challenges, such as logistics and maintenance issues, of the SIDS countries caused by their unique characteristics often make investors perceive the deployment of the off-grid renewable system in those countries as a risky project. This perception can increase the discount rate required to evaluate a renewable energy project. As shown in the sensitivity analysis on the discount rate, a higher discount rate makes renewable systems which require a huge upfront investment less attractive, and it delays the periods needed for achieving the grid parity condition. Thus, a proper assessment of risk factors of renewable projects and supportive policies for reducing those risk factors should be considered.

Moreover, the result of the sensitivity analysis on diesel price provides information about how the introduction of carbon taxes or environmental taxes can accelerate the grid parity condition in the Maldives. the Maldives is vulnerable to climate change and focuses on fuel switching from diesel 
to renewable energy options [34]. Also, tourism is one of the key parts of the Maldives' economy. Thus, the country has incentives to reduce diesel generation, which is the dominant energy system in the Maldives, emitting greenhouse gases and air pollutants. If the country introduces environmental taxes or carbon taxes, its impact is likely to be similar to the sensitivity analysis to an increase of diesel price. Thus, it can further accelerate the grid parity condition of PV systems in the Maldives. However, PV with ESS will remain as a very expensive option. As the sensitivity analysis indicates, even a $20 \%$ increase of diesel price does not bring the grid parity condition of PV with ESS and diesel generator. This implies that it will require much longer time to fully eliminate the diesel generator from the system.

In recent years, the global oil price has been increasing rapidly, and the Brent Oil price has exceeded $\$ 80$ per barrel in the late September 2018 [35]. As shown in the sensitivity analysis on diesel price, a continued trend of increasing global oil price is likely to benefit the deployment of renewable systems. Moreover, the system configuration of the project is pre-determined in the case project, and the project included high-performance but expensive batteries in the system configuration. If the trend of increasing global oil price continues and the optimal system configuration is considered, the solar photovoltaic with ESS can become a more attractive option.

Author Contributions: Conceptualization, T.Y.J. and D.K.; Data curation, J.M. and S.L.; Formal analysis, T.Y.J., D.K., J.M. and S.L.; Investigation, T.Y.J., D.K., J.M. and S.L.; Methodology, T.Y.J., D.K., J.M. and S.L.; Project administration, T.Y.J. and D.K.; Resources, T.Y.J. and D.K.; Software, J.M. and S.L.; Supervision, T.Y.J. and D.K.; Validation, T.Y.J. and D.K.; Visualization, J.M.; Writing-original draft, T.Y.J., D.K., J.M. and S.L.; Writing-review \& editing, T.Y.J. and D.K.

Funding: This research was funded by the Korea Institute of Energy Technology Evaluation and Planning (KETEP) and the Ministry of Trade, Industry \& Energy (MOTIE) of the Republic of Korea (No. 20162010103860).

Acknowledgments: This work was supported by Korea Institute of Energy Technology Evaluation and Planning (KETEP) grant funded by the Korea government (MOTIE) (20162010103860, Development and Demonstration of Multiple Linked ESS for Special Environmental Areas).

Conflicts of Interest: The authors declare no conflict of interest.

\section{Acronyms and Abbreviations}

$\begin{array}{ll}\text { SIDS } & \text { Small Island Developing States } \\ \text { PV } & \text { Photovoltaic } \\ \text { ESS } & \text { Energy Storage System } \\ \text { LCOE } & \text { Levelized Cost of Energy } \\ \text { LIB } & \text { Lithium-Ion Battery } \\ \text { VRFB } & \text { Vanadium Redox Flow Battery } \\ \text { KETEP } & \text { The Korea Institute of Energy Technology Evaluation and Planning } \\ \text { MOTIE } & \text { The Ministry of Trade, Industry and Energy of the Republic of Korea } \\ \text { HOMER } & \text { Hybrid Optimization of Multiple Energy Resources } \\ \text { CVaR } & \text { Conditional Value at Risk } \\ \text { MSSP-ABC } & \text { Multi-stage Stochastic Programming based on Artificial Bee Colony } \\ \text { MO-TE } & \text { Market Operator Transactive Energy } \\ \text { CHP } & \text { Combined Heat and Power System } \\ \text { PCS } & \text { Power Conversion System } \\ \text { O\&M } & \text { Operations and Maintenance }\end{array}$

\section{References}

1. International Renewable Energy Agency. Renewable Islands: Setting for Success. 2014. Available online: http:/ / www.irena.org/-/media/Files/IRENA/Agency/Publication/2017/Oct/GREIN_Settings_for_ Success.pdf?la=en\&hash=A57CFED57FA49FB8EEF14D3A0BFBB0721D9B731F (accessed on 1 July 2018). 
2. International Renewable Energy Agency. Renewable Power Generation Costs in 2017. 2018. Available online: http:/ / www.irena.org/publications/2018/Jan/Renewable-power-generation-costs-in-2017 (accessed on 10 August 2018).

3. International Renewable Energy Agency. Renewable Energy Roadmap: The Republic of Maldives. 2015. Available online: http:/ / www.irena.org/EventDocs/Maldives/Maldivesroadmapbackgroundreport.pdf (accessed on 10 August 2018).

4. World Bank. Renewable Energy Output (\% of total Electricity Output). 2018. Available online: https:// data. worldbank.org/indicator/EG.ELC.RNEW.ZS?view=chart (accessed on 27 September 2018).

5. Jung, T.Y.; Kim, D. A solar energy system with energy storage system for Kandooma Island, Maldives. Korean Energy Econ. Rev. 2017, 16, 24.

6. Ali, I.; Shafiullah, G.M.; Urmee, T. A preliminary feasibility of roof-mounted solar PV systems in the Maldives. Renew. Sustain. Energy Rev. 2018, 83, 18-32. [CrossRef]

7. Kaldellis, J.K.; Zafirakis, D.; Kaldelli, E.L.; Kavadias, K. Cost benefit analysis of a photovoltaic-energy storage electrification solution for remote islands. Renew. Energy 2009, 34, 1299-1311. [CrossRef]

8. Rangel, C.A.S.; Canha, L.; Sperandio, M.; Severiano, R. Methodology for ESS-type selection and optimal energy management in distribution system with DG considering reverse flow limitations and cost penalties. IET Gener. Transm. Distrib. 2018, 12, 1164-1170. [CrossRef]

9. Ghanaatian, M.; Lotfifard, S. Control of flywheel energy storage systems in presence of uncertainties. IEEE Trans. Sustain. Energy 2018. [CrossRef]

10. Li, H.; Hennessy, T. European Town Microgrid and Energy Storage Application Study. In Proceedings of the 2013 IEEE PES Innovative Smart Grid Technologies Conference (ISGT), Washington, DC, USA, 24-27 February 2013; pp. 1-6.

11. Tavakoli, M.; Shokridehaki, F.; Akorede, M.F.; Marzband, M.; Vechiu, I.; Pouresmaeil, E. CVaR-based energy management scheme for optimal resilience and operational cost in commercial building microgrids. Int. J. Electr. Power Energy Syst. 2018, 100, 1-9. [CrossRef]

12. Marzband, M.; Azarinejadian, F.; Savaghebi, M.; Pouresmaeil, E.; Guerrero, J.M.; Lightbody, G. Smart transactive energy framework in grid-connected multiple home microgrids under independent and coalition operations. Renew. Energy 2018, 126, 95-106. [CrossRef]

13. Marzband, M.; Fouladfar, M.H.; Akorede, M.F.; Lightbody, G.; Pouresmaeil, E. Framework for smart transactive energy in home-microgrids considering coalition formation and demand side management. Sustain. Cities Soc. 2018, 40, 136-154. [CrossRef]

14. Branker, K.; Pathak, M.J.M.; Pearce, J.M. A review of solar photovoltaic levelized cost of electricity. Renew. Sustain. Energy Rev. 2011, 15, 4470-4482. [CrossRef]

15. Yang, C.J. Reconsidering solar grid parity. Energy Policy 2010, 38, 3270-3273. [CrossRef]

16. Lund, P.D. Boosting new renewable technologies towards grid parity-Economic and policy aspects. Renew. Energy 2011, 36, 2776-2784. [CrossRef]

17. Baurzhan, S.; Jenkins, G.P. Off-grid solar PV: Is it an affordable or appropriate solution for rural electrification in Sub-Saharan African countries? Renew. Sustain. Energy Rev. 2016, 60, 1405-1418. [CrossRef]

18. Zou, H.; Du, H.; Brown, M.A.; Mao, G. Large-scale PV power generation in China: A grid parity and techno-economic analysis. Energy 2017, 134, 256-268. [CrossRef]

19. Mundada, A.S.; Shah, K.K.; Pearce, J.M. Levelized cost of electricity for solar photovoltaic, battery and cogen hybrid systems. Renew. Sustain. Energy Rev. 2016, 57, 692-703. [CrossRef]

20. Biondi, T.; Moretto, M. Solar Grid Parity dynamics in Italy: A real option approach. Energy 2015, 80, $293-302$. [CrossRef]

21. Said, M.; El-Shimy, M.; Abdelraheem, M.A. Photovoltaics energy: Improved modeling and analysis of the levelized cost of energy (LCOE) and grid parity—Egypt case study. Sustain. Energy Technol. Assess. 2015, 9, 37-48. [CrossRef]

22. Lambert, T.; Gilman, P.; Lilienthal, P. Micropower system modeling with HOMER. Integr. Altern. Sources Energy 2006, 1, 379-418.

23. HOMER Pro 3.12. Available online: http://www.nrel.gov/homer (accessed on 29 July 2018).

24. Bahramara, S.; Moghaddam, M.P.; Haghifam, M.R. Optimal planning of hybrid renewable energy systems using HOMER: A review. Renew. Sustain. Energy Rev. 2016, 62, 609-620. [CrossRef] 
25. Stojanov, R.; Duzi, B.; Kelman, I.; Nemec, D.; Prochazka, D. Local perceptions of climate change impacts and mitigation patterns in Male, Maldives. Geogr. J. 2016, 370-385. [CrossRef]

26. Maldives Statistics. European Commission. Available online: http://trade.ec.europa.eu/doclib/docs/2006/ september/tradoc_115814.pdf (accessed on 26 September 2018).

27. Global Landscape of Renewable Energy Finance 2018. International Renewable Energy Agency (IRENA). Available online: https:/ / www.irena.org/- / media/Files/IRENA/Agency/Publication/2018/Jan/IRENA_ Global_landscape_RE_finance_2018.pdf (accessed on 15 August 2018).

28. Global Petrol Prices. Diesel Prices, Liter. Available online: https://www.globalpetrolprices.com/diesel_ prices / (accessed on 20 July 2018).

29. Jacqueline, T.Y.; Anton, F. Moving beyond LCOE: Impact of various financing methods on PV profitability for SIDS. Energy Policy 2016, 98, 749-758.

30. Benjamin, P.; de Sandro, S.; Joao, D.B. Grid parity analysis of distributed PV generation using Monte Carlo approach: The Brazilian case. Renew. Energy 2018, 127, 974-988.

31. International Energy Agency (IEA). Energy Technology Perspectives 2010: Scenarios and Strategies to 2050; International Energy Agency (IEA/OECD): Paris, France, 2010; pp. 1-706.

32. Yeliz, S.; Carlos, M.; Amador, G.M.; Jose, C.M.; Rodrigo, E. Sensitivity and effectiveness analysis of incentives for concentrated solar power projects in Chile. Renew. Energy 2018, 129, 214-224.

33. Prachuab, P.; Bundit, L. Optimal electricity development by increasing solar resources in diesel-based micro grid of island society in Thailand. Energy Rep. 2017, 3, 1-3.

34. Ministry of Environment and Energy, Government of Maldives. Maldives' Intended Nationally Determined Contribution (INDC); Ministry of Environment and Energy, Government of Maldives: Malé, Maldives, 2015.

35. Bloomberg. Crude Oil and Natural Gas. Available online: https://www.bloomberg.com/energy (accessed on 27 September 2018).

(C) 2018 by the authors. Licensee MDPI, Basel, Switzerland. This article is an open access article distributed under the terms and conditions of the Creative Commons Attribution (CC BY) license (http:/ / creativecommons.org/licenses/by/4.0/). 